\section{ЭТНИЧЕСКОЕ ПРЕДПРИНИМАТЕЛЬСТВО БЕЗ МИГРАЦИИ (НА ПРИМЕРАХ ИЗ ТУВЫ И КАЛМЫКИИ)"}

\author{
Светлана П. Тюхтенева \\ Независимый исследователь, \\ Российская Федерация
}

\author{
ETHNIC \\ ENTREPRENEURSHIP \\ WITHOUT MIGRATION: \\ THE CASES OF TUVA \\ AND KALMYKIA
}

Svetlana P. Tyukhtenyeva Independent researcher, Russian Federation

В статье анализируются два примера современного этнического предпринимательства без миграции, которые наблюдаются в регионах России. Представлены деятельность Кимы и Вячеслава Донгаков из Тувы, Баирты Тостаевой из Калмыкии. Их проекты построены на использовании наиболее узнаваемых элементов традиционной этнической культуры и направлены на удовлетворение специфических потребностей местного сообщества, но не ограничивается только локальными клиентами. В качестве материала исследования выступили материалы авторских

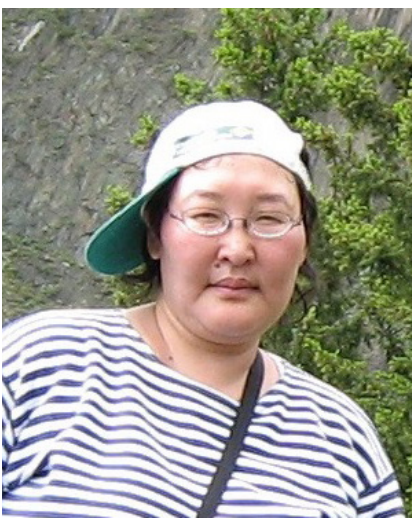

The article examines two cases of contemporary ethnic entrepreneurship which do not involve migration - those of Kima and Vyacheslav Dongak from Tuva and Bairta Tostayeva from Kalmykia. While making use of the most recognizable elements of traditional ethnic culture and catering to the specific needs of the local community, their projects appeal to clients outside of the region, too. Our research is based on personal observations and interviews with entrepreneurs, as well as on examining their project's websites and media reports.

One of the most successful examples of ethnic entrepreneurship in Siberia can be found in the succession of ethnocultural projects of various types started by V. and K. Dongaks since the 1990s. Their intention to support and develop Tuvan ethnic culture finds its outcome in expanding the range and geography of their businesses, which are currently active in Tuva, Kalmykia, Moscow and China, to самбль танца «Эдегей», и театр моды, и услуги в

\footnotetext{
" Статья подготовлена при финансовой поддержке РФФИ, проект 17-01-00407-ОГН ОГН-А «Юг России: этнические предприниматели “дома" и за его пределами (опыт социально-экономической адаптации)».

The article was prepared with the financial support of the RFBR, project 17-01-00407-OGN OGN-A "South of Russia: ethnic entrepreneurs "at home" and beyond (experience of socio-economic adaptation)."
}

Тюхтенева Светлана Петровна - доктор исторических наук, независимый исследователь, г. Горно-Алтайск, Российская Федерация. Эл. адрес: kerel63@mail.ru

Tyukhteneva Svetlana Petrovna, Doctor of History, Independent Researcher, Gorno-Altaysk, Russian Federation.E-mail: kerel63@mail.ru 
сфере пошива и изготовления одежды, и этнокультурные комплексы с нацииональной кухней.

Пример Б. Тостаевой из Калмыкии демонстрирует нацеленность на повседневность, в первую очередь, жителей республики. Она также опирается на те же основы традиционной культуры - пищу, одежду и жилище. Делается ставка и на потенциал развиваемого при поддержке республиканских властей событийного туризма. В бизнесе используется и тема этники, и космополитичная тема.

Тувинские и калмыцкие этнические предприниматели находятся в благоприятной социальной среде в сравнении с этническими предпринимателямимигрантами. Их проекты развиваются в русле не спадающего процесса национального возрождения. Но основная проблема для них заключается в сложной экономической ситуации, характерной для аграрных, животноводческих республик. Большое значение для развития бизнеса имеет личностный фактор, идентичность человека, в котором должен присутствовать целый спектр идентичностей, в том числе этнокультурная, гендерная, локальная, гражданская, которые оказывают значительное влияние на его деятельность. Отмечается стремление этнических предпринимателей к разнообразию, которое ведет к диверсификации их деятельности. Этничность предпринимателя рассматривается как этнический ресурс, поскольку повышает конкурентоспособность бизнеса.

Ключевые слова: этническое предпринимательство; Тува; Калмыкия; этничность; идентичность; Вячеслав Донгак; Кима Донгак; Баирта Тостаева; тувинцы; калмыки; «Эдегей»; национальный костюм; национальная кухня name just a few areas. The projects include the children's dance ensemble "Edegey", a theater of fashion, a tailor shop, and ethnocultural centers which serve authentic traditional foods.

The case of B. Tostayeva in Kalmykia mainly focuses on the everyday life of the region. Her projects also rely on the same staples of traditional culture - apparel, food and housing. With support from regional authorities, the projects are also dealing with event tourism. Bairta Tostayeva's business makes use of both ethnic and cosmopolitan overtones.

When compared to ethnic entrepreneurs who migrate out of their region, their two counterparts in Tuva and Kalmykia find themselves in a much more advantageous social environment. Their projects follow within the course of ever intensifying national rebirth, but have to grapple with economic difficulties typical for agrarian regions which rely on animal farming. Also important for the success of the business is the personality factor, which comprises a whole host of identities - ethnocultural, gender, local, civic, and others, all of them informing the activity of the person. A drive towards variety is a common feature among ethnic entrepreneurs, which allows them to diversify their businesses. The very ethnicity of an entrepreneur can be seen as an asset, since it can improve their competitiveness.

Keywords: ethnic entrepreneurship; Tuva; Kalmykia; ethnicity; identity; идентичHocms; Vyacheslav Dongak; Kima Dongak; Bairta Tostayeva; Tuvans; Kalmyks; «Edegey»; traditional garment; ethnic cuisine

\section{Введение}

Этническое предпринимательство, основанное на производстве и реализации традиционной национальной одежды, пищи и жилища - «трех китов» этнографии - в регионах России зародилось в конце 1990-х годов. Исследовательская парадигма ученых и практиков в целом сосредоточена на изучении этнического предпринимательства мигрантов из стран бывшего Союза ССР, вслед за наработанной к тому времени опытом и теорией зарубежной науки по исследованию такого опыта адаптации мигрантов в странах Запада и Америки. Мне же более интересно этническое предпринимательство без миграции.

В статье на основе собственных полевых этнографических материалов и данных из открытых источников, в том числе из Интернета, предпринята 
попытка рассмотреть два кейса. Один на примере деятельности Кимы и Вячеслава Донгаков из Тувы, второй - Баирты Тостаевой из Калмыкии. На их примерах я намерена показать, что этническое предпринимательство как вид экономической деятельности, в процессе и для ведения которого предприниматель использует этнические, родственные, земляческие, дружеские сети и связи, производя товар или услугу, востребованные именно в этом этнокультурном сообществе и представляющее его как для внутриэтнического, так и для внешнего «потребления», можно и нужно исследовать.

Цельюстатьи является исследование этнического предпринимательства в регионах России, осуществляемого представителями местного населения, построенного на использовании наиболее узнаваемых элементов традиционной этнической культуры и направленного на удовлетворение специфических потребностей местного сообщества, но не ограничивается только локальной, коэтничной клиентурой, и только этими символами их этничности. Эвристический потенциал изучения этнического предпринимательства в регионах России, как мне представляется, достаточно большой.

\section{Пример из Тувы}

Одним из наиболее успешных примеров такого рода предпринимательства в Сибири мне представляется деятельность

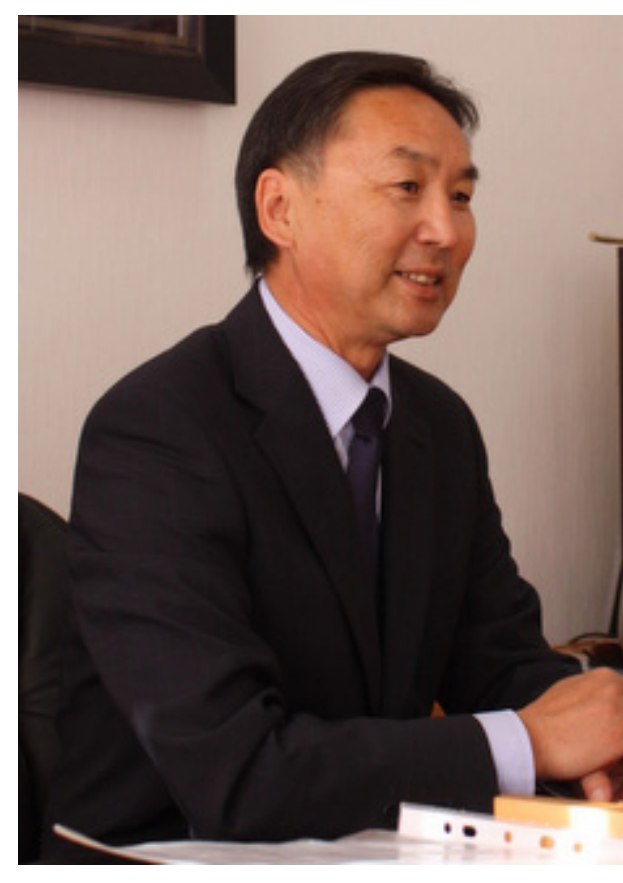

Фото 1. Вячеслав Донгак. Фото Ч. Ламажаа, 2010 г. Photo 1. Vyacheslav Dongak, photo by Ch. Lamazhaa, 2010. супружеской пары Вячеслава и Кимы Донгаков, создавших с 1990-х годов целый каскад проектов этнокультурного содержания, но разных форм.

Несколько слов о Донгаках. Вячеслав Октябревич Донгак - профессиональный режиссер-балетмейстер. Много лет работал в государственном ансамбле песни и танца «Саяны», в том числе его художественным руководителем (1992-2002 гг.). Занимал руководящие посты в сфере культуры Республики Тыва, имеет государственные награды. Работал в других российских регионах, также ставил танцы, балеты, мюзиклы для коллективов стран ЮгоВосточной Азии.

Свою самостоятельную творческую деятельность выразил в собственных проектах фонде культуры, проводящем конкурсы красоты, всевозможные детские творческие конкурсы, детский ансамбль «Эдегей», открывший свое 
модельное агентство; при творческих коллективах работает швейная мастерская национального костюма «Оваадай». За два десятка лет существования «Эдегей» завоевал большое количество гран-при, призовых мест на международных и российских фестивалях. Большой успех сопровождает дизайнерские творения В. Донгака, ставшего модельером стилизованной одежды, которую шьют в его мастерской и демонстрируют модели агентства.Причем показ моды происходит всегда в форме танцевальных шоу, которые сам хореограф и ставит.

Все свои проекты В. Донгак осуществлял и продолжает осуществлять вместе со своей супругой К. Донгак, которая с 1990-х годов уже имела предпринимательский опыт, и которая в союзе с ним стала директором ансамбля, его главным помощником, вдохновителем.

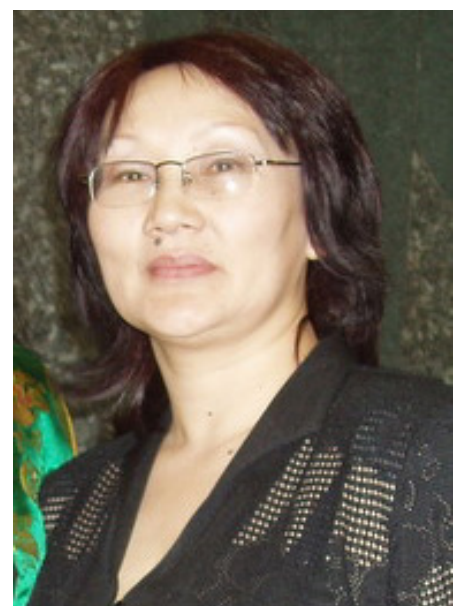

Фото 2. Кима Донгак. Фото Ч. Ламажаа, 2005 г. Photo 2. Kima Dongak, photo by Ch. Lamazhaa, 2005.

В 2011 г. их усилиями, в том числе когда В. Донгак возглавлял министерство культуры республики, в 45 километрах от столицы Тувы Кызыла был открыт этнокультурный комплекс «Алдын Булак» с юрточным городком, рестораном с национальной кухней для туристов. К. Донгак первое время руководила проектом, развивала его. Затем такой же туристический этнокультурный комплекс она создавала близ г. Элисты в Калмыкии. В 2017 г. К. Донгак открыла ресторан «Алдын Булак» в Москве. Тем самым их бизнес практически был диверсифицирован и перерос за рамки собственно искусства, хореографии. Почти за двадцать лет деятельность семьи хореографа демонстрирует не только желание поддерживать и развивать

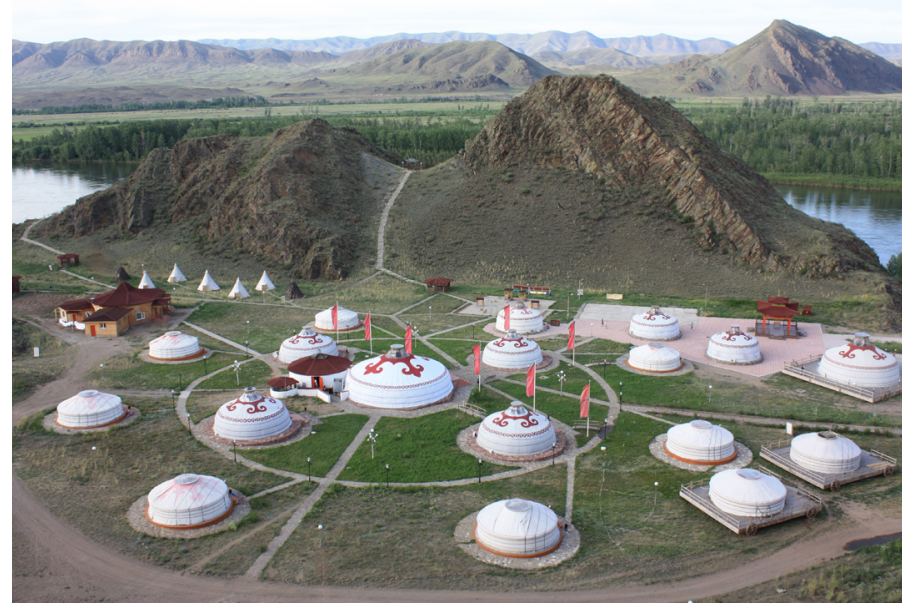

Фото 3. Этнокультурный комплекс "Алдын Булак" в Туве. Фото А. Папына, 2014 г.

Photo 3. Ethnocultural center Aldyn Bulak in Tuva, photo by A. Papyn, 2014. национальную культуру тувинцев, но и расширять поле деятельности, географию проектов.

Несомненно, что творческая деятельность семьи Донгаков показывает яркий пример этнического предпринимательства в Туве - успешного, раз нообразного. Наиболее общественно значимым эффектом следует назвать инспирацию четой Донгак этнического предпринимательства в Республике Тыва не только в сфере пошива и изготовления одежды, но и другой продукции, в том числе 


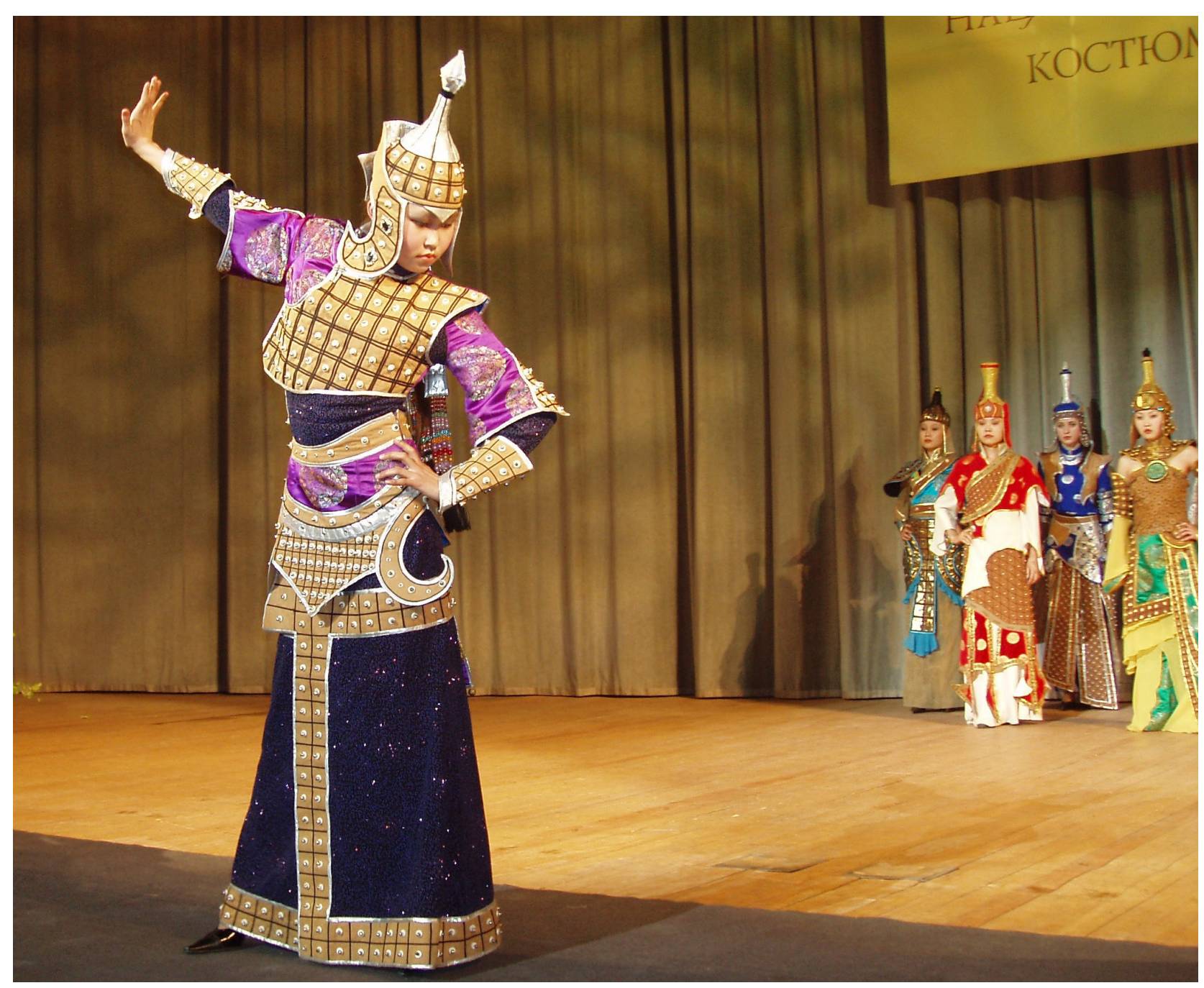

Фото 4. Показ коллекции "Кан-Кыс" театра моды и танца "Эдегей" в Москве. Фото Ч. Ламажаа, 2005 г. Photo 4. The Kan Kys collection by the theatre of fashion and dance Edegey on display in Moscow, 2005, photo by Ch. Lamazhaa.

традиционных ремесел, и услуг, ориентированных на развитие народной культуры в новом осмыслении. Полагаю, что с их начинаниями в республике стали столь популярными различные республиканские конкурсы швей и закройщиков, семинары для дизайнеров, швей, изготовителей сувениров, занимающихся народно-художественными промыслами.

Заслуженный деятель искусств Республики Тыва, лауреат Государственной премии Республики Тыва, режиссер, балетмейстер В. О. Донгак основные идеи своего творчества формулирует так: «оживить костюмную историю наших предков», презентовать «театрализованную подачу дефиле» национальной одежды (Сандуков, 2015: Электр. ресурс). Главный месседж В. Донгака, направленный населению региона - это мысль о том, что «с возрождения культуры, обычаев и традиций воскреснут и другие области республики, духовность - генератор развития нашей экономики» (там же). Идея, 
направленная вовне - миру: традиционная одежда кочевников Центральной Азии эстетична, презентабельна и перспективна (там же).

О востребованности идей Вячеслава Донгака, основанных на синтезе традиций родной ему тувинской народной культуры и традиций европейской хореографии и высокой моды, реализованных в его творчестве и в бизнесе, может свидетельствовать факт приглашения его занять пост Президента Международной академии Моды мировых монголов. На эту должность он был избран в ноябре 2014 г. на итоговом заседании академии в г. Улан-Баторе. Академия была создана заинтересованными дизайнерами - профессионалами в области национального костюма монголоязычных кочевых народов Центральной Азии. Среди них есть модельеры Монголии, России, Китая и других стран, журналисты и главные редакторы модных СМИ, ученые, бизнесмены из сферы туризма (Заслуженный деятель ..., 2015: Электр. ресурс). С того же 2015 г. В. Донгак стал приглашенным художественным руководителем Театра национального искусства Внутренней Монголии (там же).

Как я уже сказала, последнее направление предпринимательской деятельности Донгаков, прежде всего К. Донгак, - это этнокультурные комплексы. Первый из них представляет собой базуотдыха, состоящую из юрт, чумов, сауны и пр., а также большой юрты-ресторана с традиционной тувинской кухней. Несомненно, что проработавший в течение года (с 2017 по май 2018 г.) в Москве одноименный ресторан тувинской кухни «Алдан-Булак» несет такие же смыслы, которые вкладывались при создании комплекса в Туве: традиционная кухня народа кочевой культуры на фоне исторических реконструкций предметов материальной культуры тувинцев и древних скифов, в том числе и одежды, в стилизованном помещении в виде традиционного жилища. В планах К. Донгак - создание в Москве юрточного городка с рестораном тувинской кухни.

Как говорит К. Донгак, поясняя цели своей деятельности и творчества В. Донгака, ими движет не желание быстро заработать, и не коммерческая составляющая вовсе, а желание распространять тувинскую культуру в самых разных формах, желание популяризировать ее, увековечить. «У нас уникальный бизнес, - сказала Кима Чозаровна в интервью мне, - мы работаем с сакральными вещами. Сакральность не может быть не интересна миру, и мы счастливы от мысли, что не напрасно занимаемся национальным костюмом, народными танцами, кухней, юртами - жилищем предков и их пропагандой. Вот уже больше двух десятков лет ни один год нами не прожит впустую: мастерклассы, презентации, поездки, выступления. Наш потенциал неисчерпаем, всегда находится какой-то новый ракурс предыдущих дел, рождается новая идея, новый свет, и все это делает нас сильнее!»

Примеры роста их бизнеса от театра танца к ателье и фэшн-индустрии, а также к ресторанному бизнесу с акцентом на национальную кухню демонстрируют стабильность предпринимательской деятельности Донгаков. 


\section{Пример из Калмыкии}

Если предпринимательство Вячеслава и Кимы Донгаков посвящено репрезентации культуры тувинцев, и, шире, азиатских народов России и мира, а адресатом их творчества является внешний (по отношению к Туве) мир, то примердеятельности другой этнической предпринимательницы,из Республики Калмыкия, демонстрирует нацеленность на повседневность, в первую очередь, жителей самой степной республики.

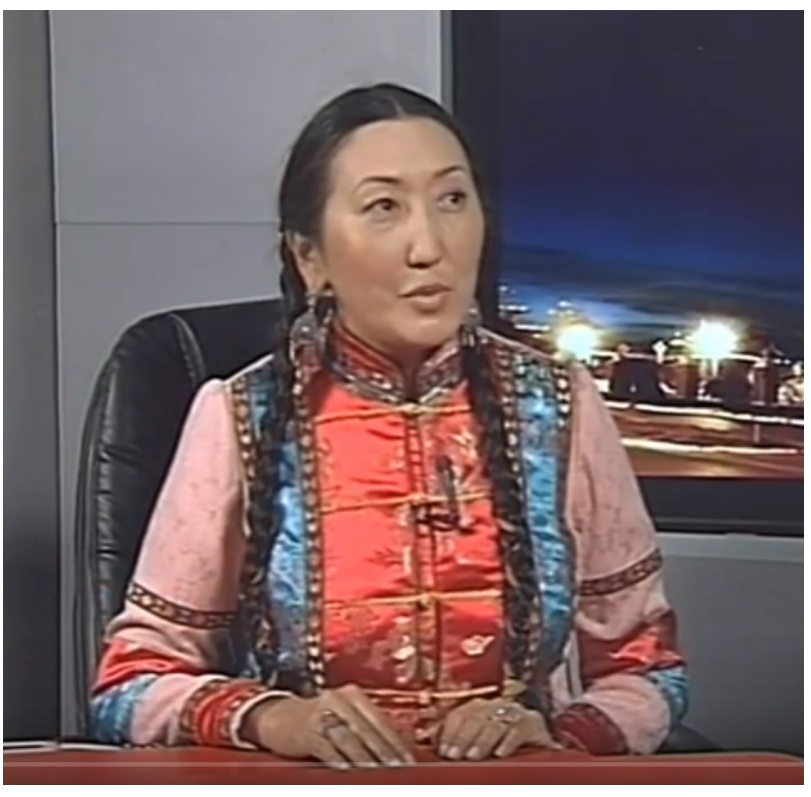

Фото 5. Баирта Тостаева. Скриншот видеофрагмента телепередачи «Народные новости» телеканала «Хамдан» 28 сентября 2016 г.

Photo 5. Bairta Tostayeva. A screenshot of the Narodnye Novosti (People's News) broadcast on Hamdan TV channel, September 28, 2016.

Предприниматель Баирта Тостаева из Элисты так же, как Вячеслав и Кима Донгаки, ведет свой бизнес по пути диверсификации, опираясь на те же основы традиционной культуры пищу, одежду и жилище. Сегодня этническая предпринимательница услугам элистинцев и гостей города и Калмыкии предлагает калмыцкую и монгольскую кухню в ресторане «Легенда» (http://www. легендаресторан.рф), бизнес-ланчи русской, калмыцкой и европейской кухонь в пресс-кафе «Репортер», пошив предметов одежды в калмыцком стиле в ателье «Иньглян». Ресторан «Легенда» был открыт в 2012 г. и по сей день Б. Тостаевой удалось удержать репутацию заведения с хорошей кухней, аутентичным интерьером и внимательным обслуживанием ${ }^{1}$. По словам самой Тостаевой, большую часть прибыли этого ресторана дают банкеты, и лишь треть - посещения туристов и гостей Элисты.

Вместе с тем, судя по разнообразию предлагаемых посетителям программ, предпринимательница вполне очевидно делает ставку и на потенциал развиваемого при поддержке республиканских властей Калмыкии событийного туризма. В основе проекта ресторана «Легенда» лежит концепт Востока на основе традиционной калмыцкой народной культуры, синтезированный с творчески переработанными популярными сюжетами других регионов и культур. Так, ресторан предлагает как отдельное мероприятие калмыцкую

\footnotetext{
${ }^{1}$ См. фотографии отзывов посетителей из книги жалоб и предложений на сайте ресторана:

http://www.легенда-ресторан.pф/reviews?page=5
} 


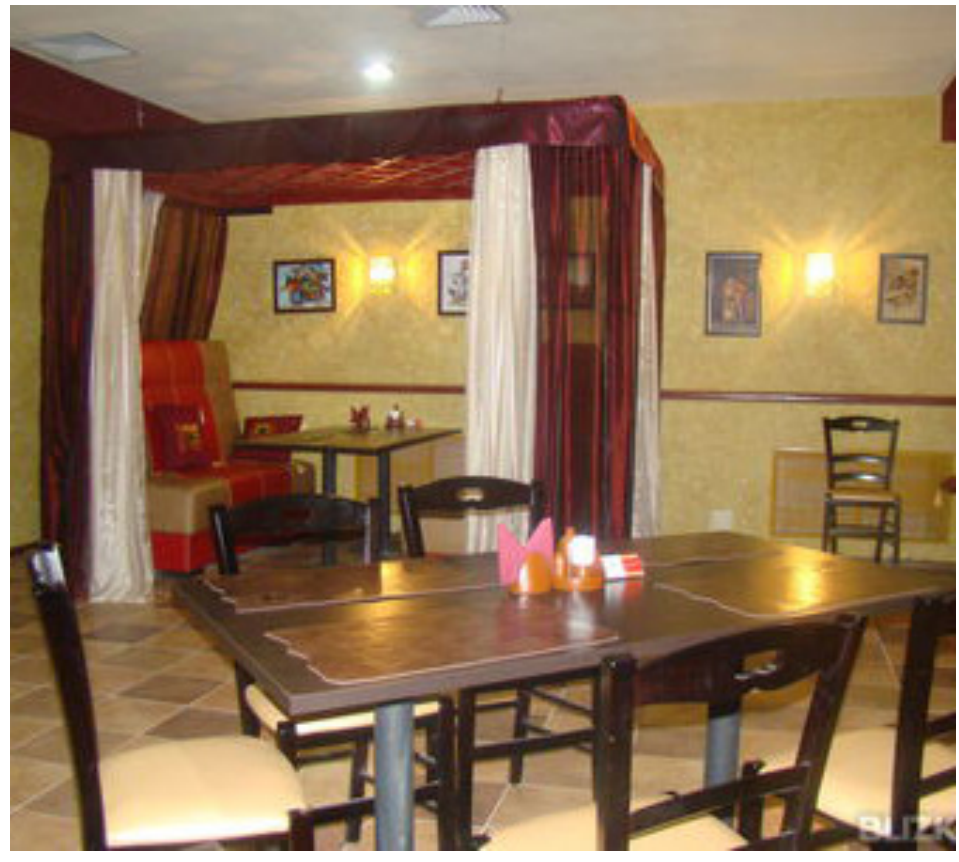

Фото 6. Интерьер ресторана «Легенда». Фото с сайта ресторана.

Photo 6. The interior of The Legend, photo courtesy of the restaurant's website. чайную церемонию с фотографированием в национальной одежде в процессе приготовления и распития чая под руководством ведущей в войлочной юрте. Иными словами, национальный колорит, являющийся одним из важных составных частей предпринимательства Баирты Тостаевой, вполне осознается ею как часть стратегии конкурентоспособности и успешно используется. Наряду с этим, в другом ее заведении кафе «Репортер», в интерьере которого обыгран концепт журналистского путешествия по миру, она реализует идею космополитичной кухни для современного человека вне его этнических предпочтений. Таким образом, предпринимательница использует в своем бизнесе и тему этники, и космополитичную тему.

Особого внимания заслуживает другой проект Б. Тостаевой - ателье пошива ойратской одежды «Иньглян», открытый в 2016 г. Направление ателье создание национальной калмыцкой одежды, как сказано на его странице на сайте ресторана «Легенда».

В основе этого проекта ателье и дизайнерской студии лежит чисто личностный фактор, который можно определить как стремление Б. Тостаевой к разнообразию:

«Я предприниматель, год назад стала заниматься общественной деятельностью - развитием и популяризацией калмыцкого костюма. Плюс еще мы немного затрагиваем тему о традициях и обычаях, пытаемся развивать калмыцкий язык, в общем всего по чуть-чуть. Это я говорю об ассоциации женщин Калмыкии “Иньглян”. На базе этой ассоциации мы создали дизайнерскую студию “Иньглян”, где шьем одежду, которую можно носить в повседневной жизни» (Чонаев, 2017: Электр. ресурс).

«Мы так увлеклись этим делом, что остановить нас уже невозможно. Многие женщины нашего города сидят дома и скучают. ... Найти нас можно в “Фейсбуке”, “В Контакте” и “Одноклассниках". Мы открыли страницы в этих социальных сетях под названием Ассоциация женщин 
Калмыкии “Иньглян”. Планов много и все они связаны с нашей деятельностью. Причем такие интересные проекты, как создание видеоблогов с уроками и мастер-классами. Было бы хорошо, если к нам примкнули молодые и энергичные девушки с креативным мышлением. Вот в чем у нас дефицит! А в целом, последние три года, а особенно 2016 год запомнились как очень насыщенные на события и впечатления. Много интересных людей и много новых мест я открыла для себя. Побывала там, куда давно собиралась. Поняла одно самое главное: "Не то, где ты, а с кем ты”. Люди - это основное богатство. И в Калмыкии - самые лучшие люди. Только они или мы об этом почему-то забываем (Басангова, Электр. ресурс).

Б. Тостаева утверждает, что ей нравится быть калмычкой, одно из интервью с ней имеет такой заголовок: «...Мне нравится быть калмычкой» (там же). При этом

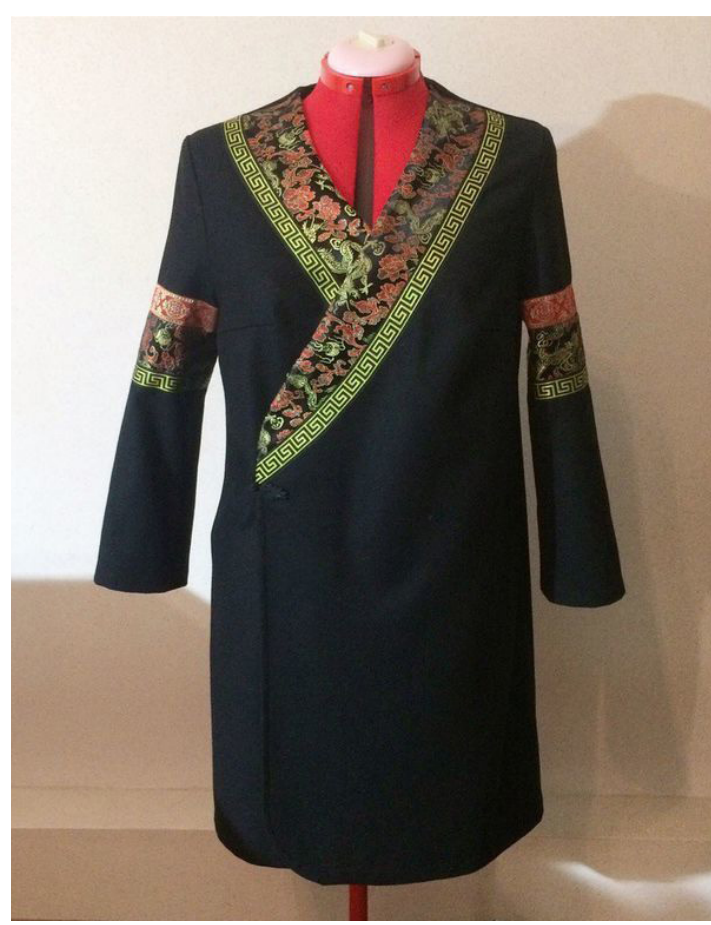

Фото 7. Образеи женского пиджака дээл, который предлагает отелье ойратской одежды Иньглян. Фото со страницы ателье на сайте ресторана «Легенда».

Photo 7. Daal, a women's jacket from the Oirat tailor shop Inglyan. Photo courtesy of the tailor shop's page at The Legend's website. предпринимательница в другом интервью сама анализирует, каким образом происходило становление ее этнокультурной идентичности и самоосознание себя:

«В самом раннем возрасте я не ощущала себя калмычкой. Я видела себя русской с калмыцкой внешностью девочкой. Находясь здесь в Элисте, в Калмыкии, я, тем не менее, не находила в себе этнической принадлежности и с какого-то момента меня это стало напрягать. Эта неполноценность у меня копилась и в итоге я стала понимать, что мне в жизни чегото не хватает. Позже я охарактеризовала это словосочетанием “недостаток гармонии” (Чонаев, 2017: Электр. ресурс);

«В 2006 году я ездила в Монголию и купила там себе платье. Когда я его надела, то почувствовала, что во мне что-то изменилось. Не могу объяснить это словами, но я как будто прониклась энергетикой монгольской степи мощной, строгой и в то же время мягкой. И я поняла, вот она - гармония! Я всегда немного рукодельничала - шила, кроила, перелицовывала одежду, но вот как сшить калмыцкое традиционное платье я не знала. Я хотела сшить платье, которое можно было надевать, как говорится “хоть в пир, хоть в мир”, а те платья, которые носили наши артисты, меня не 
устраивали. Потому что со всеми этими пайетками, стразами, бисером и прочими блестяшками, которые лепят на концертные костюмы артистов, я бы выглядела как новогодняя елка в супермаркете на распродаже. Ну не может такого быть, чтобы наши бабушки и прабабушки носили такую непрактичную одежду, думала я и оказалась права. И я стала шить - первое платье, второе, а потом это вошло в привычку» (там же).

Создание дизайнерской студии и ателье в 2016 г. стало логичным продолжением пережитого инсайта, о котором говорит Б. Тостаева: «открытию» собственной этнокультурной идентичности «способствовало» монгольское платье, купленное ею в 2006 г. За десять лет после того, как она ощутила гармонию междутем, как и кем она себя ощущает, и что на ней надето, Б. Тостаева выработала собственный стиль, основанный на сознательном компромиссе между традиционной народной культурой калмыков и желанием возрождать и развивать эту культуру.

Б. Тостаева носит традиционную калмыцкую прическу замужней женщины, стилизованную одежду:

«И вот я шью свои платья по образу и подобию калмыцкой повседневной одежды, ношу их, всем это очень нравится и многие мои близкие подруги сказали “ах, я тоже себе хочу такое” и стали уговаривать меня шить для других женщин. Так родилось наше женское движение “Иньглян”. Мы приглашали к себе самых разных людей и узнавали у них - как должна вести себя женщина-калмычка в семье, в быту, на работе, как выстраивать правильные отношения сдетьми, с мужем, с его родственниками. Нам хотелосьпонять, что из себя представляла женщина раньше, какой она стала сейчас и как можно адаптировать полезные традиции к современной реальности. Потому что мы никак не можем быть похожи на тип “западных женщин” и ориентирование на Запад в этом смысле для нас не приемлемо» (там же).

Последний по времени реализованный Б. Тостаевой проект, связанный с изготовлением стилизованной одежды, более, чем предыдущий ее бизнес, связан не только с этнокультурной идентичностью современной женщины калмычки. В нем отражаются, как в зеркале, все те процессы, которые происходят в Элисте и в Калмыкии в целом. Охарактеризовать эти процессы можно как рост интереса к этнической культуре.

В своих интервью и других публичных высказываниях, в частности, в выступлениях на телеканале Хамдан-ТВ Б. Тостаева неоднократно говорит о необходимости возрождать традиционную культуру, буквально воссоздавая по деталям одежду, утраченную вследствие депортации калмыков зимой 1942 года в Сибирь, а также рецептуру и технологию приготовления пищи, интерьера жилища. 


\section{Этническое предпринимательство без миграции}

В фокусе моего исследования - этническое предпринимательство без миграции. Большая часть исследований этнического предпринимательства в мире посвящена изучению того, каким образом вчерашние мигранты или их потомки ведут бизнес в ситуации высокой конкуренции, часто дискриминации, нахождения в меньшинстве (расовом, этническом, культурном, языковом, религиозном и т. д.) для улучшения условий своей жизни, повышения благосостояния семьи, и, в конечном итоге, успешной адаптации в новых условиях. Все исследователи согласны с тем, что этническое предпринимательство - это один из главных видов и способов адаптации мигранта к ситуации в принимающем сообществе. Главное отличие бизнеса гражданина страны от бизнеса мигранта - это мобилизация мигрантом своих ресурсов, главными из которых являются его этническая, конфессиональная и земляческая идентичности, тогда как коренному жителю страны реципиента таких усилий прилагать не приходится (см. подробнее: Уолдингер, Олдрич, Уорд, 2008). К числу ставших классическими примерами современного этнического предпринимательства можно отнести появление чайнатаунов (Chinatown - «китайский город») в самых разных городах мира, или пример предпринимательской деятельности евреев, выходцев из Одессы, в районе Брайтон-Бич («маленькая Одесса») в Бруклине, Нью-Йорке, США, массовое производство и реализация корейских салатов в России.

Вместе с тем, за последние годы интерес научного сообщества к этническому предпринимательству и этнической экономике в регионах России способствовал появлению соответствующих публикаций, в которых идет речь именно об этническом предпринимательстве без миграции (Тишков, 2005; Радаев, 1993; Этнические рынки в России, 2015; Ахметов, 2017; Еременко, 2014; Рыжова, 2003; Мулукова, 2008 и др.). Как следует из работ, освещающих региональные аспекты этнического предпринимательства в республиках юга России, в программах государственной поддержки предприятий малого и среднего предпринимательства в России, не предусмотрена особая поддержка этнического предпринимательства. Между тем, считают исследователи, потенциал у последнего вида бизнеса достаточно велик.

Так, к примеру, в Адыгее значительная часть потребляемых товаров массового спроса, более половины животноводческой продукции, около 4/5 овощей производится именно силами этнических предпринимателей (Тамов, Тамова, Бабалян, 2016: 78). В Дагестане этноэкономика растет быстрыми темпами в сфере услуг: свадьбы, похороны, юбилеи, мусульманские праздники и т. д. В одной Махачкале, по сведениям М. А. Багомедова, сейчас более тридцати залов, предназначенных для свадебных торжеств единовременной вместимостью более 20 тысяч мест (Багомедов, 2011: 79). В другой северокавказской рес- 
публике, в Карачаево-Черкессии, даже в годы мирового экономического кризиса численность индивидуальных предпринимателей, этнических предпринимателей в том числе, росла: «В 2009 г. было зарегистрировано 16100 индивидуальных предпринимателей.В 2008 г. их количество составило 15623 чел. и выросло по сравнению с 2007 г. (13778 чел.) на 11,2\%» (Атаева, 2012: 53).

\section{Условия для ведения этнического предпринимательства в Калмыкии и в Туве}

Этническое предпринимательство мигрантов обычно рассматривается как деятельность, осуществляемая в неблагоприятных социальных условиях, когда предприниматели находятся в расовом, этническом, культурном, языковом, религиозном меньшинстве и/или дискриминации по этим признакам, или социокультурной стигматизации и геттоизации.

Два рассмотренных мною кейса находятся в иных условиях. Они реализуются в субъектах Российской Федерации, которые относятся к числу так называемых «национальных республик», когда коренное население насчитывает более половины от всей численности: $82 \%$ тувинцев от общего числа населения в Туве и 57,4\% - в Калмыкии. С одной стороны, тувинские и калмыцкие этнические предприниматели находятся в благоприятной социальной среде, их проекты развиваются в русле не спадающего процесса национального возрождения, который развернулся в регионах с 1990-х гг. Но с другой стороны, основная проблемадля них заключается в сложной экономической ситуации,характерной для аграрных, животноводческих республик. В этой связи уровень конкуренции среди тех, кто работает в сфере услуг, розничных продаж и общественного питания, чрезвычайно высок.

Социально-экономические характеристики двух регионов сходны: они не имеют больших производств, которые являлись бы локомотивом экономики, а такжезависимыотфедеральногобюджета,внихвысокийуровеньбезработицы, низкий уровень оплаты труда и т. п. Уровень конкуренции, таким образом, в сфере торговли и услуг крайне высок, поскольку борьба идет за довольно специфичного клиента-работника бюджетной сферы, ограниченного вдоходах невысокими в целом заработными платами, и молодежь, в том числе студентов. Благодаря тому, что деятельность предпринимателей осуществляется на территории столичных городов, в Кызыле и в Элисте, они могут рассчитывать, помимо местных жителей, и на гостей, посещающих эти регионы. Главными из них прежде всего можно назвать представителей федеральных и окружных министерств и ведомств, регулярно производящих проверки деятельности подведомственных учреждений, в связи с чем потребность в наличии заведений общественного питания с национальной кухней и учреждений 
культуры, репрезентирующих местную культуры, стабильна и постоянна. Помимо этого типа гостей региона, в летнее время обе республики посещаются немногочисленными пока туристами.

\section{Личность этнического предпринимателя}

Рассматриваемые примеры этнического предпринимательства неразрывно связаны с личностью предпринимателя, в котором присутствуют важные параметры, называемые исследователями термином «фиксированное разнообразие» (Alexandre-Leclair, 2014: 158). Речь идет о том, что в идентичности человека сочетается целый спектр идентичностей, в том числе этнокультурная, половая, локальная, гражданская, которые оказывают значительное влияние на его деятельность. Рассматриваемые мною примеры этнического предпринимательства как раз демонстрируют, каким образом культура и этническая принадлежность выступают определяющими факторами в выборе сферы деятельности и стратегии ведения бизнеса. Два кейса из двух разных регионов России подтверждают исследование А. Пеку, в котором он утверждает, что этничность предпринимателя дает определенные преимущества в бизнесе, и посему многие исследователи называют ее этническим ресурсом (Pécoud, 2010: 62-64).

Тувинский кейс показывает пример того, что стремление специалиста в сфере культуры и искусства дать свое новое видение, новую интерпретацию традиционной этнической культуры привело к созданию новой формы ее репрезентации. Основным мотивом деятельности В. Донгака, очевидно, является развитие новой формы искусства, синтетического по сути, но с явным тувинским «лицом». Главное в его акциях - эстетическая составляющая, направленная на развитие народной одежды от повседневной утилитарности к высокой моде. Этому способствует форма подачи одежды от-кутюр в виде театрализованного действа с использованием традиционных музыкальных инструментов и хореографии. Предпринимательство в данном кейсе - не самая очевидная цель деятельности, но ее следствие.

Другой, калмыцкий, кейс представляет пример этнического предпринимательства в более явном, если можно так выразиться, виде. Судя по высказываниям, основная мотивация деятельности Б. Тостаевой основана на ее этнокультурной идентичности и желании не только возрождать культуру калмыцкого народа, но и развивать, совершенствовать ее, делая более современной и понятной. Помимо того, что она самозанятый человек, зарабатывающая на жизнь сама, Тостаева также создает новые рабочие места, внося вклад в развитие экономики своей республики, в ее деятельности важную роль играет просветительская составляющая. 
Так, к примеру, Б. Тостаева совместно с ученым, ведущим научным сотрудником Калмыцкого научного центра РАН, доктором искусствоведения С. Г. Батыревой инициировала в декабре 2016 года проведение мастер-классов по войлоковалянию и вышивке по войлоку. Их провела Екатерина Адьяева, учредитель общественной организации «Гильдия мастеров народных ремесел Республики Калмыкия». С журналистами «Хамдан-ТВ» она провела передачу о процессе и технологии приготовления традиционных калмыцких пельменей, а также других блюд народной кухни, приглашая к участию ученых этнографов (Махан Шёлтягян, 2017: Электр. ресурс). Все проводимые мастер-классы сняты на видео и выложены в социальных сетях, чтобы любой человек смог ими воспользоваться («Вкусная Калмыкия» ..., 2016: Электр. ресурс).

Логично было бы в случае деятельности Б. Тостаевой развитие ее бизнеса вверх или вниз по технологической цепи - производство и реализация полуфабрикатов, к примеру, или инвестиции в фермерство с целью удешевления мясной продукции. Однако, в стратегии ведения бизнеса, как оказалось, важна и ее гендерная идентичность. В приведенном выше интервью предпринимательница, говоря об открытии дизайнерской студии «Иньглян», рассказывает, что вместе с подругами она создала «Ассоциацию женщин Калмыкии» с одноименным названием. То есть, желание узнать больше не только об одежде калмыков, но и об обычаях и традициях с участием женщин и их роли в семейной, общественной жизни, привело Тостаеву к мысли об объединении с другими заинтересованными в том же женщинами. Апробация идеи на уровне общественной организации показала перспективность пошива стилизованной калмыцкой одежды и наличие в обществе спроса, что и стало решающим фактором для диверсификации бизнеса - создания ателье «Иньглян». Будучи женой, мамой и бабушкой, Б. Тостаева задумывается о создании одежды в стилизованном национальном стиле и для детей, и для мужчин, а также спортивной одежды.

\section{Заключение}

Таким образом, рассмотренные примеры деятельности этнических предпринимателей из двух регионов России показывают, что в этом виде бизнеса важна личность самого предпринимателя. К числу наиболее важных факторов, воздействующих на мотивацию деятельности и стратегии конкурентоспособности предпринимателя, следует отнести его культурную, гендерную и этническую идентичности. Кроме того, важно отметить стремление этнических предпринимателей к разнообразию, которое ведет к диверсификации их деятельности.

Проведенное исследование этнического предпринимательства в регионах России, ведущегося представителями местного населения, использующими 
в качестве ресурса и стратегии традиционную этническую культуру, множество различных видов социальных связей, подтверждает, что изучение этнического предпринимательства без миграции вполне возможно и перспективно.

На мой взгляд, важным и существенным отличием между этническим предпринимательством без миграции и этническим предпринимательством мигрантов выступает тот контекст, в котором они действуют. Если мигрант вынужден адаптироваться в изначально некомфортной и подчас агрессивной среде, то этнический предприниматель - не мигрант находится в комфортной, как минимум, ситуации. Использование своей этничности как ресурса и мигрантом, и не мигрантом, преследует совершенно схожие цели. Однако, в случае с мигрантом его этничность - это еще и способ мобилизации актором этничности солидаризующихся с ним групп людей.

Собственно контекст, на фоне которого действуют и мигрант, и местный, я понимаю, как состоящий из культуры - родной для местного и чужой для мигранта, языка, законодательства. Безусловно, этот контекст включает множество самых разных факторов, влияющих на деятельность этнического предпринимателя, но названные - наиболее важные.

Этнический предприниматель, реализующий свои бизнес идеи у себя «дома», окружен людьми, говорящими с ним на одном языке, он понимает и разделяет ценности культуры окружающих его людей, и, наконец, он защищен законодательством как гражданин страны. Этнический предприниматель мигрант, как правило, лишен всего этого.

Этническое предпринимательство в России, как мне представляется, будучи важным для человека способом адаптации к социальной и экономической ситуации, помимо этого, играет весьма значимую для этнокультурного сообщества роль - способствует сохранению и развитию этнической культуры.

Благодаря этому феномену в глобализирующемся и унифицирующемся мире появляются такие вещи, как стилизованная в стиле этник одежда, позволяющая одному человеку самовыразиться и отличаться от безликой толпы, а другому сохранять и развивать культурное наследие своих предков.

\section{СПИСОК ЛИТЕРАТУРЫ}

Атаева, Л. М. (2012) Традиционные и инновационные направления развития этнического предпринимательства // Региональная экономика: теория и практика. № 9 (240). С. 51-55.

Ахметов, В. Я. (2017) Роль этнического предпринимательства и этнической кооперации в сохранении и возрождении российского села (на материалах Республики Башкортостан)// Биосферное хозяйство: теория и практика. № 2 (3). C. 40-50. 
Багомедов, М. А. (2011) Новые тенденции этноэкономического поведения в Республике Дагестан // Вопросы структуризации экономики. № 3. С. 78-84.

Басангова, С. Баирта Тостаева: мне нравится быть калмычкой [Электронный peсурс] // Элистинский курьер. URL: http://ekgazeta.ru/articles/1712-bairta-tostaeva-mne-nravitsya-byt-kalmychkoj (дата обращения: 06.02.2018).

«Вкусная Калмыкия» 2 выпуск гость Байрта Тостаева ресторан «Легенда» (2016) [Электронный ресурс]//YouTube.com. 21 марта.URL: https://www.youtube. com/watch?time_continue $=546 \& \mathrm{v}=-\mathrm{rO} 9 H S f D n L Q$ (дата обращения: 06.02.2018).

Еременко, С. Л. (2014) Влияние этнической идентичности на экономическое поведение россиян // Общество и право. № 1 (47). С. 291-295.

Заслуженный деятель искусств Республики Тыва Вячеслав Донгак отмечает 60-летие (2015) [Электронный ресурс] // Тува.Азия. 22 августа. URL: https://www. tuva.asia/news/tuva/8154-dongak60.html (дата обращения: 06.02.2018).

Махан Шёлтягян (2017) [Электронный ресурс] // Ok.ru. 19 января. URL: https:// ok.ru/video/239964131669 (дата обращения: 06.02.2018).

Мулукова, Л. (2008) Феномен этнического предпринимательства на примере татар города Ижевска // Бизнес. Общество. Власть. № 2 (2). С. 21-39.

Радаев, В. В. (1993) Этническое предпринимательство: мировой опыт и Россия // Полис. Политические исследования. № 5. С. 79-87.

Рыжова,Н.П. (2003) Трансграничный рынок в Благовещенске: формирование новой реальности деловыми сетями «челноков» // Экономическая социология. T. 4. № 5. C. $54-71$.

Сандуков, А. (2015) Вячеслав Донгак: Где бы я ни работал, я всегда остаюсь тувинцем [Электронный ресурс] // ARD. 25 мая. URL: http://asiarussia.ru/persons/7619/ (дата обращения: 06.02.2018).

Тамов, А. А., Тамова, М. К., Бабалян, Э. Б. (2016) Развитие малого бизнеса в проблемных регионах с использованием потенциала этноэкономического сегмента // Вестник Адыгейского государственного университета. Вып. 3 (185). C. $75-80$.

Тишков, В. А. (2005) Рыночная экономика и этническая среда // Общество и экономика. № 12. С. 20-37.

Уолдингер, Р., Олдрич, Х., Уорд, Р. (2008) Этнические предприниматели / перевод М. С. Добряковой // Экономическая социология. Т. 9. № 5. С. 30-55.

Чонаев, Д. (2017) Баирта Тостаева: «Мы не ожидали такого успеха!» [Электронный ресурс] // Элистинский курьер. http://ekgazeta.ru/articles/2077bairta-tostaeva-my-ne-ozhidali-takogo-uspekha (дата обращения: 06.02.2018). 
Этнические рынки в России: пространство торга и место встречи (2015) / науч. ред. В. И. Дятлов, К. В. Григоричев. Иркутск : Иркутский государственный университет. 343 с.

Alexandre-Leclair, L. (2014) Diversity as a motive for entrepreneurship? The case of gender, culture and ethnicity // Journal of Innovation Economics \& Management. № 14. P. 157-175.

Pécoud, A. (2010) What is ethnic in an ethnic economy? // International Review of Sociology. Vol. 20. № 1, March. P. 59-76.

Дата поступления: 20.03.2018 2.

\section{REFERENCES}

Ataeva, L. M. (2012) Traditsionnye i innovatsionnye napravleniia razvitiia etnicheskogo predprinimatel'stva [Traditional and innovative trends in the development of ethnic entrepreneurship]. Regional'naia ekonomika: teoriia i praktika, no. 9 (240), pp. 51-55. (In Russ.).

Akhmetov, V. Ia. (2017) Rol' etnicheskogo predprinimatel'stva i etnicheskoi kooperatsii v sokhranenii i vozrozhdenii rossiiskogo sela (na materialakh Respubliki Bashkortostan) [The role of ethnic entrepreneurship and ethnic cooperation in the preservation and revival of the Russian village (on the materials of the Republic of Bashkortostan)]. Biosfernoe khoziaistvo: teoriia i praktika, no. 2 (3), pp. 40-50. (In Russ.).

Bagomedov, M. A. (2011) Novye tendentsii etnoekonomicheskogo povedeniia v Respublike Dagestan [New trends in conducting ethnoeconomics in Dagestan]. Voprosy strukturizatsii ekonomiki, no. 3, pp. 78-84. (In Russ.).

Basangova, S. Bairta Tostayeva: mne nravitsia byt' kalmychkoi [Bairta Tostayeva: I like being a Kalmyk]. Elistinskii kur'er [online] Available at: http://ekgazeta. $\mathrm{ru} /$ articles/1712-bairta-tostaeva-mne-nravitsya-byt-kalmychkoj (access date: 06.02.2018). (In Russ.).

«Vkusnaia Kalmykiia» 2 vypusk gost' Bairta Tostayeva restoran «Legenda» ["Delicious Kalmykia" Issue 2: Bairta Tostayeva and the Legend restaurant] (2016). YouTube.com, 21 Mars [online] Available at: https://www.youtube.com/watch?time_ continue $=546 \& v=-$ rO9HSfDnLQ (access date: 06.02.2018). (In Russ.).

Eremenko, S. L. (2014) Vliianie etnicheskoi identichnosti na ekonomicheskoe povedenie rossiian [Influence of ethnic identity on economic behavior of the Russians]. Obshchestvo i pravo, no. 1 (47), pp. 291-295. (In Russ.).

Zasluzhennyi deiatel' iskusstv Respubliki Tyva Viacheslav Dongak otmechaet 60-letie [Honored artist of the Republic of Tuva Vyacheslav Dongak celebrates his 
60th anniversary] (2015). Tuva.Asia, 22 August [online] Available at: https://www. tuva.asia/news/tuva/8154-dongak60.html (access date: 06.02.2018). (In Russ.).

Makhan Sheltiagian (2017). Ok.ru, 19 January [online] Available at: https://ok.ru/ video/239964131669 (access date: 06.02.2018). (In Russ.).

Mulukova, L. (2008) Fenomen etnicheskogo predprinimatel'stva na primere tatar goroda Izhevska [The phenomenon of ethnic entrepreneurship on the example of the Tatars of Izhevsk]. Biznes. Obshchestvo. Vlast', no. 2 (2), pp. 21-39. (In Russ.).

Radaev, V. V. (1993) Etnicheskoe predprinimatel'stvo: mirovoi opyt i Rossiia [Ethnic entrepreneurship: global experience and Russia]. Polis. Politicheskie issledovaniia, no. 5, pp. 79-87. (In Russ.).

Ryzhova, N. P. (2003) Transgranichnyi rynok v Blagoveshchenske: formirovanie novoi real'nosti delovymi setiami «chelnokov» [Transborder market in Blagoveshchensk: the rise of the new reality via shuttle traders' business networks]. Ekonomicheskaia sotsiologiia, vol. 4, no. 5, pp. 54-71. (In Russ.).

Sandukov, A. (2015) Viacheslav Dongak: Gde by ia ni rabotal, ia vsegda ostaius' tuvintsem [Vyacheslav Dongak: wherever I work, I always remain a Tuvan]. ARD, 25 May [online] Available at: http://asiarussia.ru/persons/7619/ (access date: 06.02.2018). (In Russ.).

Tamov, A. A., Tamova, M. K. and Babalian, E. B. (2016) Razvitie malogo biznesa $\mathrm{v}$ problemnykh regionakh $\mathrm{s}$ ispol'zovaniem potentsiala etnoekonomicheskogo segmenta [Small business development in the troubled regions using the ethnoeconomic segment potential]. Vestnik Adygeiskogo gosudarstvennogo universiteta, vol. 3 (185), pp. 75-80. (In Russ.).

Tishkov, V. A. (2005) Rynochnaia ekonomika i etnicheskaia sreda [Market economy and ethnic environment]. Obshchestvo i ekonomika, no. 12, pp. 20-37. (In Russ.).

Uoldinger, R., Oldrich, Kh. and Uord, R. (2008) Etnicheskie predprinimateli [Ethnic entrepreneurs] / transl. by M. S. Dobriakova. Ekonomicheskaia sotsiologiia, vol. 9, no. 5, pp. 30-55. (In Russ.).

Chonaev, D. (2017) Bairta Tostayeva: «My ne ozhidali takogo uspekha!» [Bairta Tostayeva: "We did not expect such a success!»]. Elistinskii kur'er [online] Available at: http://ekgazeta.ru/articles/2077-bairta-tostaeva-my-ne-ozhidali-takogo-uspekha (access date: 06.02.2018). (In Russ.).

Etnicheskie rynki $v$ Rossii: prostranstvo torga i mesto vstrechi [Ethnic markets in Russia: bargaining space and meeting place] (2015) / Ed. by V. I. Diatlov and K. V. Grigorichev. Irkutsk, Irkutskii gosudarstvennyi universitet. 343 p. (In Russ.).

Alexandre-Leclair, L. (2014) Diversity as a motive for entrepreneurship? The case of gender, culture and ethnicity. Journal of Innovation Economics \& Management, no. 14 , pp. 157-175. 
Pécoud, A. (2010) What is ethnic in an ethnic economy? International Review of Sociology, vol. 20, no. 1, March, pp. 59-76.

Submission date: 20.03.2018.

\section{Для цитирования:}

Тюхтенева С. П. Этническое предпринимательство без миграции (на примерах из Тувы и Калмыкии) [Электронный ресурс] // Новые исследования Тувы. 2018, № 2. URL: https://nit.tuva.asia/nit/article/view/776 (дата обращения: дд.мм.гг.). DOI: 10.25178/nit.2018.2.8

\section{For citation:}

Tyukhtenyeva S. P. Ethnic entrepreneurship without migration: the cases of Tuva and Kalmykia. The New Research of Tuva, 2018, no. 2 [on-line] Available at: https://nit.tuva. asia/nit/article/view/776 (accessed: ... ). DOI: 10.25178/nit.2018.2.8 